\title{
Research on the Reform of College Physical Education Based on the Concept of Lifelong Physical Education
}

\author{
Li Shuang \\ Division of Sports Science and Physical Education of Dalian University of Science and Technology, \\ Dalian, Liaoning, 116052
}

Keywords: lifelong physical education; College students; College Physical Education

\begin{abstract}
The concept of lifelong physical education is a teaching concept that has been put forward for more than half a century. It emphasizes that physical exercise should run through our study, work and life. So we should exercise consciously. However, college students, a huge group, are seriously lacking this concept, which deserves people's deep consideration. In view of the implementation of the concept of lifelong physical education in College Physical Education classes, this paper analyses the problems existing in College Physical Education from the perspective of the concept of lifelong physical education and puts forward four improvement measures in order to promote the reform of College Physical Education in China.
\end{abstract}

\section{Introduction}

As early as the 1960s, the concept of lifelong sports was put forward by Paul Langer, a French writer. As a branch of lifelong education, lifelong physical education is gradually recognized in the follow-up life and education process. The concept of lifelong physical education emphasizes that the study of physical education should not be confined to the school's very limited tens of minutes of physical education classes. Physical education has traces to follow in all aspects of our life, learning and work. Therefore, from birth to the end of life, we should always carry out physical education and physical education. Even in daily life and work, we should consciously take part in physical exercise, and take physical education learning as an indispensable part of life.

At present, although the national society is advocating the concept of lifelong physical education, the physical fitness of college students in society is very worrying. Many surveys show that the overall trend of College Students'physical fitness from admission to graduation is declining, which also shows that the concept of lifelong physical education has not yet been applied in University teaching. True implementation, the following table is the statistical results of the sample survey of College Students'sports survey. It can be seen that the amount of College Students' sports is far from enough, and the majority of people do not exercise. 


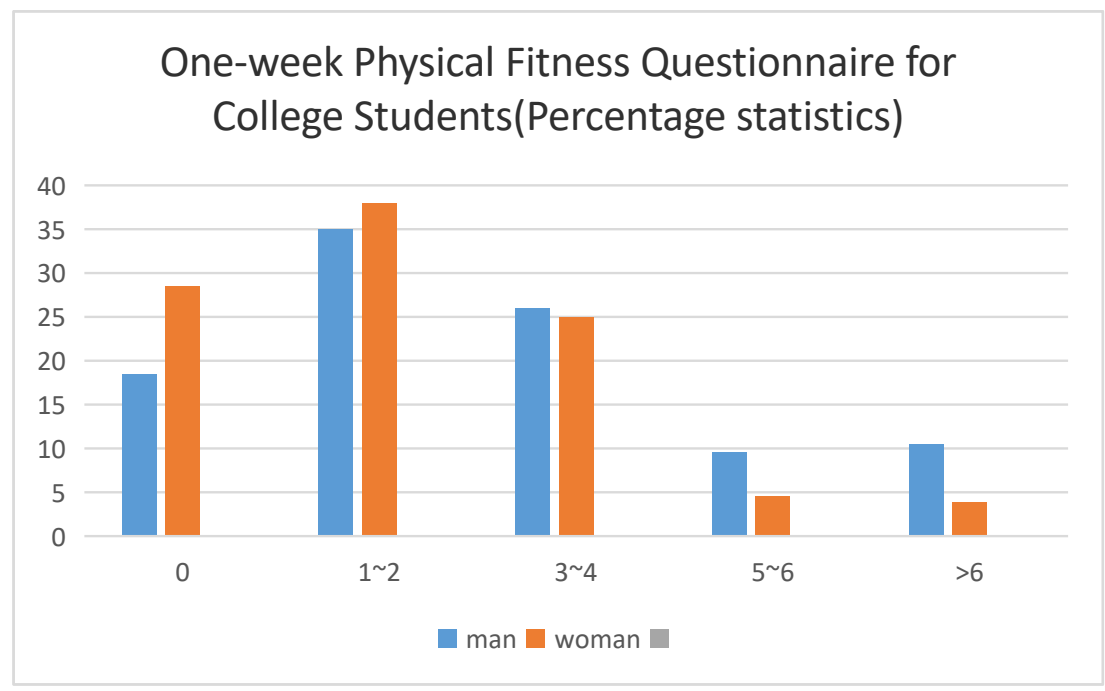

Figure 1 Questionnaire on the Average Weekly Exercise Number of College Students

\section{Problems in College Physical Education Teaching from the Perspective of Lifelong Physical Education}

\subsection{Weak Awareness of Lifelong Sports Concept}

At present, in the teaching of physical education in Colleges and universities in China, there is a general problem of weak awareness of lifelong physical education concept, which is not conducive to the cultivation of students'lifelong physical education consciousness, but also to the improvement of the teaching effect of physical education in Colleges and universities. This is mainly reflected in the following aspects: First, for the administrators of physical education in Colleges and universities, there is not enough. The awareness of lifelong physical education and insufficient attention to physical education teaching have affected the improvement of the quality of physical education teaching. Secondly, for some college physical education teachers, in the process of teaching, there is also a lack of lifelong sports concept, which has not been effectively conveyed to students, making students unable to form lifelong sports awareness in the process of physical education learning, and thus unable to develop lifelong sports habits, although in learning sports knowledge and skills. Yes, but it is difficult to really understand the value of sports, so it is difficult to guarantee the learning effect of sports knowledge and skills. Thirdly, for college students, in the process of learning sports knowledge, they have not formed lifelong sports consciousness, at the same time, they have not learned enough about lifelong sports related knowledge, which has affected the improvement of their learning effect.

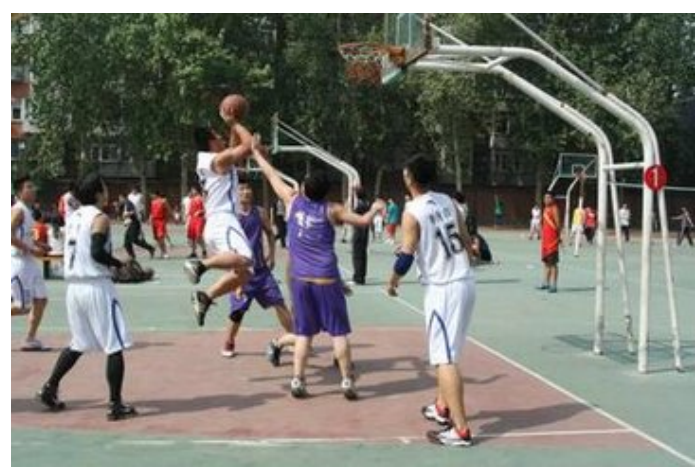

Figure 2 College Students Exercising 


\subsection{The Single Teaching Method of Physical Education}

Due to the influence of traditional physical education teaching mode, nowadays in many colleges and universities in our country, the physical education teaching mode presents a single and tedious situation, mainly teacher-led, indoctrinating teaching mode for students. In the physical education practice teaching, the teaching mode mainly focuses on explanation and demonstration, and does not fully respect the main status of students. Compared with individual differences, it is not difficult enough for students with better physical education foundation, but it is too difficult for students with weaker physical education foundation, which greatly reduces students'interest and enthusiasm in physical education learning, leads to a significant reduction in students' learning effect, and thus has a significant negative impact on the improvement of physical education teaching quality. Surface effect.

\subsection{The Comprehensive Quality of Teachers is Not High Enough}

Physical education teachers are the important software elements influencing the teaching effect of physical education in Colleges and universities. They are the main body of teaching in direct contact with students. They are the implementers and guiders of the whole teaching process. They play a vital role in the teaching process. Every word and deed of physical education teachers in the teaching process will exert a subtle influence on students'places.It plays an important role in guiding and setting an example for students'thoughts and behaviors. Therefore, the improvement of the overall quality of physical education teachers is a very important link in the reform of physical education teaching in Colleges and universities. However, at present, most of the P.E. teachers in Colleges and universities in China still use the traditional P.E. teaching mode in the teaching process. Their teaching ideas, concepts, goals and abilities have not been updated and improved in a timely manner. They only aim at strengthening students'physique and improving students' P.E. skills.However, it ignores the more needs of students in sports learning. This is extremely detrimental to the improvement of the whole physical education teaching effect.

\subsection{Physical Education Teaching Resources are Relatively Scarce}

Nowadays, in the process of construction of sports teaching sites and facilities in Colleges and universities, due to too much emphasis on cultural and professional courses, the emphasis on sports courses is not high enough, while neglecting the construction of sports venues and facilities, resulting in a serious lack of sufficient sports venues and facilities in many colleges and universities.This has affected the smooth progress of physical education teaching.Nowadays, only a small number of colleges and universities in China have relatively perfect sports venues and facilities, and a large number of them do not meet the corresponding standards for the construction of sports venues and facilities. In addition, because the maintenance and management of sports venues usually require a certain amount of capital investment, so there are many colleges and universities, usually in the holding of some sports games or teaching work will open the stadium, in peacetime seldom open to students.

It has seriously affected the students'sports training and the improvement of students' sports learning efficiency. 
3. Reform Measures of Physical Education in Colleges and Universities from the Perspective of Lifelong Physical Education

\subsection{Integrating Physical Education in Colleges and Universities into the Concept of Lifelong Physical Education}

From the perspective of lifelong physical education, in order to effectively strengthen the level of physical education reform and improve the quality of physical education in Colleges and universities, we should first actively change the concept of teaching and actively integrate it into the concept of lifelong physical education at all levels of physical education in Colleges and universities. In the actual physical education teaching activities, we should not only cultivate students'own sports skills and professional knowledge, but also guide them to actively establish correct sports consciousness, exert a subtle influence on students' concepts in various physical education activities, and ultimately effectively cultivate their lifelong sports concepts. College physical education teaching should take lifelong physical education as the guiding ideology and teaching goal, actively cultivate college students'lifelong physical education habits and concepts, and lay a solid foundation for their lifelong physical education. At the same time, it is necessary to strengthen the construction of the teaching staff of physical education in Colleges and universities. Physical education teachers are required to establish lifelong sports consciousness first, to serve as a lifelong sports model for students, and to actively improve their professional skills and teaching level, so as to promote the effective improvement of the comprehensive quality of teaching.

\subsection{Enriching the Teaching Content According to the Needs of Students}

In order to cultivate students'lifelong sports concept, it is necessary to actively introduce sports teaching content that meets students' needs and interests so as to realize the continuous enrichment of sports teaching content. Physical education teachers in Colleges and universities should fully understand students'psychological characteristics and internal needs, diversify teaching content, and add some new teaching projects with strong operability, so as to promote students' interest in physical exercise, actively participate in and actively establish the concept of lifelong physical education.

\subsection{Scientific Evaluation of Physical Education Activities in Colleges and Universities}

In order to improve students'comprehensive physique and physical exercise, and cultivate students' lifelong physical education consciousness, it is necessary to incorporate scientific evaluation mechanism into college physical education teaching, and to evaluate the whole process of physical education activities more rationally in order to improve teaching quality. When evaluating the effect of physical education teaching activities, we should break the original situation of single evaluation and realize the co-evaluation of teachers and students through multiple evaluation methods. Teachers and students should also pay attention to the diversification of evaluation methods in the evaluation of physical education teaching activities. By summing up various evaluation indicators and weighting them, comprehensive evaluation results can be obtained.

\subsection{Strengthening the Construction of Physical Education Infrastructure in Colleges and Universities}

In order to realize the reform of physical education in Colleges and universities from the 
perspective of lifelong physical education, it is necessary to effectively strengthen the physical education teaching infrastructure in Colleges and universities. Colleges and universities should increase investment in sports infrastructure construction, strengthen the construction of gymnasiums, timely update sports equipment, improve venues and facilities, promote students to achieve more smooth physical exercise, effectively mobilize their enthusiasm for sports and cultivate lifelong sports awareness in a good environment of facilities support and activities.

\section{Conclusions}

Although the concept of lifelong physical education was put forward earlier, according to the group of College students, there are still many aspects needed to be improved in the reform of College Physical Education from the perspective of lifelong physical education. We need to pay more attention to the problems existing in the reform and take necessary measures to improve them actively.So that we can promote the smooth progress of College Physical Education reform.

\section{References}

[1]Yao Chen.Research on the Reform and Development of College Physical Education from the Perspective ofLifelong Physical Education [J/OL].Sports World (Academic Edition), 2018(11):147+149[2018-12-10]. https://doi.org/10.16730/j.cnki.61-1019/g8.2018.11.103.

[2]Mu Zhen.Research on the Reform of Physical Education in Colleges and Universities in China from the Perspective of Lifelong Physical Education[J].Contemporary sports science and technology,2018,8(29):12-13.

[3]Zhu Wenjun.Exploration and Research on the Reform of Physical Education in Colleges and Universities from the Perspective of Lifelong Physical Education [J].Intelligence, 2018(28):153.

[4]Cao Jin.Research on the Reform and Innovation of Physical Education in Colleges and Universities under the Background of Lifelong Physical Education[J].Journal of Tianjin Academy of Educational Science,2018(04):72-74.

[5]Li Lin.On the Reform of College Physical Education under the Concept of Lifelong Physical Education [J]. Contemporary sports science and technology,2018,8(24):96+98. 